\title{
LA MENTIRA Y LA ESTRUCTURA SOCIAL
}

\author{
Lynn Hirschkind
}




\section{LA MENTIRA Y LA ESTRUCTURA SOCIAL}

Este trabajo versa sobre la mentira en la forma en que se le usa en una comunidad campesina en el sur del Ecuador. Describe cómo y por qué la gente miente y relaciona su práctica a la estructura social de la localidad.

Pretende ofrecer una explicación tanto histórica como estructuralfuncional del lugar que ocupa la mentira en esta comunidad.

La palabra mentira se usa en este trabajo en el más amplio sentido del término: una falsa representación de lo que uno considera verdadero, que va desde una ligera y sugestiva deformación del hecho hasta una falsedad total y fantasiosa; un complejo invento de elementos del pasado y del futuro. En términos generales mentir implica consciente intención de engañar. Se sugiere al lector eliminar las connotaciones morales que generalmente tiene el término mentira y examinar las descripciones expuestas en este trabajo con la imparcialidad que requiere un fenómeno social no estudiado.

Su ubicuidad en la parroquia La Mar (un seudónimo) de la provincia del Cañar me llamó la atención y me obligó a pensar que yo ignoraba una parte importante de lo que se había escrito sobre etnografía andina y también sobre teoría antropológica. La mentira ha sido tratada en algunos análisis, pero no se le ha dedicado un tratamiento más profundo (cf. Fals-Borda 1962; Foster 1965, 1967; Chagnon 1974: 92; Reichel-Dolmatoff 1961: 104, 112, 446). Mentir aquí significa ser amable, sociable, colaborador y generoso. La gente se asegura entre sí que todo está bien, que no hay problemas entre ellos, que tienen buena voluntad e intenciones honorables hacia los otros en una serie de mentiras usuales. La violencia se evita y la cooperación mutua se hace posible mediante esfuerzos regulares para ocultar los verdaderos sentimientos, deseos y conocimientos. Por medio de falsedades y silencios se mantienen los valores de la comunidad, al igual que la continuidad y el orden en actividades individuales y colectivas. Las instituciones locales económicas, políticas, sociales, religiosas y de parentesco pueden funcionar cómodamente con la ayuda de mentiras juiciosas. 
Aunque este ensayo trata exclusivamente de la mentira en un contexto rural del Ecuador, esto no implica que esta área sea única o que la mentira no sea parte integral de la vida cotidiana en cualquier otro lugar. Al contrario, la literatura etnográfica documenta esta práctica en asentamientos rurales y urbanos a lo largo y ancho del mundo.

Al analizar la mentira a nivel personal y de estructura social en una localidad específica, mi intención es proporcionar un ejemplo detallado para que sea comparado con otras áreas y también sugerir que un rol integracional juega en ambos niveles de la realidad social.

\section{Parroquia La Mar: Características físicas y sociales.}

La parroquia La Mar está ubicada en la cordillera Oriental de los Andes en la provincia del Cañar y tiene una extensión de cerca de $600 \mathrm{~km}^{2}$. La población total fue de 2.964 habitantes en 1974 (censo de población), pero la aldea La Mar tenía 306. La topografía de la región es quebrada, con áreas pequeñas de tierras planas y suavemente inclinadas. Un río atraviesa la parroquia y es alimentado por muchos arroyos pequeños. Con un promedio anual de lluvia de aproximadamente 1.400 centímetros, el área tiene suficiente pluviosidad. La parroquia incluye pastos naturales tipo páramo, bosques nativos y tierras agrícolas y pastizales entre los 1.200 y $4.100 \mathrm{mt}$. sobre el nivel del mar. En contraste con las tierras secas, erosionadas y exhaustas típicas de los Andes centrales del Ecuador, La Mar tiene un verde $\mathrm{y}$ fértil aspecto.

Al comienzo de este siglo unas pocas haciendas extensas (latifundios) de 5.000 a 10.000 hectáreas cada una ocupaban la mayor parte de la tierra, mientras que propiedades independientes medianas y pequeñas estaban ubicadas en los alrededores. Un alto porcentaje de la población dependiente vivía en las haciendas con derechos y obligaciones de huasipungueros ${ }^{1}$. Estas haciendas poco a poco disminuyeron en tamaño debido a divisiones por herencias y venta de parcelas. Como consecuencia de la Reforma Agraria de la década de los años 60, los hacendados tuvieron que liberar sus tierras de campesinos dependientes, lo que consiguieron mediante ventas y expulsiones. Así, en nuestros días, lo que queda de las haciendas es muy reducido, entre 500 y 3.000 hectáreas que incluyen amplias áreas de páramo y bosque. Estos remanentes están rodeados de propiedades pequeñas y medianas pertenecientes tanto a los antiguos peones de las 
haciendas como a campesinado independiente. Una hacienda de 4.000 hectáreas se ha transformado en una Cooperativa con cerca de 50 familias miembros.

La economía local está basada en una mezcla de productos para subsistencia y para mercadeo. La más importante cosecha y / base de la alimentación diaria es el maíz, pero también se cultiva fréjoles, patatas, arveja, trigo y cebada; los últimos tres fundamentalmente para la venta. Existe ganado para obtener leche y carne y para arar. De la mayor parte de la leche se hace quesillo que se vende cada viernes en La Mar con el fin de obtener dinero para comprar la ración semanal de arroz, azúcar, sal, manteca. Se cría también cerdos, ovejas, gallinas y caballos, estos últimos necesarios para el transporte. Las haciendas usan los servicios de jornaleros ocasionales y cuentan también con unos pocos trabajadores a tiempo completo que contribuyen para el ingreso de algunas familias.

Hay una significativa diferenciación económica entre los campesinos, basada fundamentalmente en el acceso a la tierra. En general, mientras más tierra o cosechas se tenga, mientras más ganado se críe, el ingreso se torna más alto. El tamaño de las propiedades privadas, excepto las haciendas, varía entre menos de una hectárea a varios centenares de hectáreas. Al margen del tamaño de la parcela, todos los habitantes del sector rural de La Mar se consideran a sí mismo campesinos y ponderan con vehemencia su pobreza. Desde el punto de vista de un forastero, la gente de La Mar tiene un alto nivel de vida comparado con los campesinos de otras partes del Ecuador: son propietarios de algunas de las mejores tierras del área (partes bajas de los valles, bosques, laderas con inclinación suave), poseen ganado y ninguno sufre hambre.

En términos locales se reconoce dos grupos raciales: indios (runas) y blancos (blancos) $)^{2}$. Los blancos superan ampliamente en número a los indios: la población total de indios es de aproximadamente 500, la mayor parte de los cuales pertenecen a la cooperativa. Los indios son deferentes con los blancos y los blancos desprecian a los indios como norma general. El status económico importa poco en la calificación de lo inter-étnico. Los dos grupos tienen igual ubicación económica, aunque las posiciones sociales más elevadas (por ejemplo hacendado, empleado, profesor, cura) están ocupadas exclusivamente por blancos. 


\section{Cómo se miente en La Mar: Quién, cuándo y por qué.}

En la parroquia La Mar todos son mentirosos sin que importe edad, sexo, status económico y racial. Los niños que luchan por aprender a caminar son ya proclives a dar falsas informaciones proyectando una imagen de inocencia con sus caras y sus voces. Con mucho tiempo de vida en esta experiencia la gente mayor se torna experta en este tipo de información.

Una serie de ejemplos relacionados con el problema central de la propiedad de una parcela de tierra demuestran cuán importante puede ser la habilidad para mentir; en este caso un viejo demuestra cómo plantear un reclamo frente a una situación aparentemente imposible de lograrla. Dos indios-de edad habían comprado a su patrón pequeñas parcelas colindantes en los tiempos de la reforma agraria. Uno de los compradores, Taita Atoc, construyó una casa en su lote y fue a trabajar desbrozando, cultivando y sembrando pasto simultáneamente. El otro comprador, Taita Zhibry, vivía en otra parte y arrendaba su parcela a otros vecinos. Luego de la muerte de Taita Zhibry, Taita Atoc aprovechó la oportunidad para reclamar que el lote del difunto había sido suyo. Explicó cómo había comprado la parcela hace algunos años pagando dos cabezas de ganado y S/. 8.000 enviados por medio del patrón a Taita Zhibry. Puesto que el patrón no había devuelto los animales ni el dinero, por un acuerdo tácito, Taita Atoc tenía derecho a la tierra. Taita Atoe explicó las circunstancias confusas diciendo que el viejo Zhibry pudo haber tratado de rehusar la transacción por pura obstinación y posiblemente por senectud, no existiendo otra explicación para que no quisiera vender tierra que no necesitaba.

Los patrones y campesinos ricos no se diferencian entre sí por el uso de argumentos relacionados con empobrecimiento cuando se trata de manipular la verdad. Indios y blancos mienten con diferencias mínimas en técnicas, frecuencia y contenidos tan sólo en circunstancias individuales. Aunque con frecuencia se informa en etnografía andina que blancos y mestizos consideran la mentira una falta exclusiva de los indios, aquí hay consenso en el sentido de que en La Mar cualquiera puede ser mentiroso.

Hay notables variaciones de las personas en lo que se refiere a habilidad y frecuencia para mentir. Unas pocas personas tergiversan casi todo lo que ven con ligeras y extremas falsedades. Otros tienen consumada habilidad para generar credibilidad anticipando los resultados de una mentira y entendiendo las mentes y motivaciones de quienes les escuchan en relación con la finalidad de sus manipulaciones. 
Para ilustrar, una muy hábil técnica para mentir, el patrón que vendió las parcelas a sus peones se aprovechó de la muerte de Taita Zhibry para plantear su propio reclamo. El patrón tenía una reputación bien ganada y documentada de violencia y arbitrariedad para imponer su voluntad, sabía que era temido. El supo que no había título legal alguno ni convenio escrito relacionados con la venta de la parcela en referencia. Supo que habían varias personas que disputaban la propiedad del lote: Taita Atoe, la hija de Taita Zhibry, el vecino propietario, en frente de Taita Atoe y una pareja joven con grandes necesidades de tierra. En estas condiciones el patrón hizo conocer que la tierra le pertenecía a él, que nunca había sido vendida aunque él ya no era propietario de la hacienda y no había visto la parcela por 10 años. Amenazó con enviar a su hijo para que monte guardia en la tierra y golpee a quien quiera que trate de tomar posesión de ella; una clara advertencia para que Taita Atoe y la heredera se mantuvieran fuera. Aceptó un pago inicial al vecino terrateniente y le dijo que esperara hasta que se definieran asuntos relacionados con títulos. (Este propietario tenía razón para creer que él tenía la mejor posibilidad para adquirir la tierra: la Ley de Reforma Agraria establece que los propietarios de tierras adyacentes al lote puesto en venta deben tener opción preferencial para comprarlo y que se requiere de su decisión por escrito de no querer hacer la compra antes de que el lote pueda ser vendido a cualquier otra persona). Mientras tanto la hija de Taita Zhibry había hecho varios viajes a la agencia de Reforma Agraria para tratar de convencer a esta institución que le dieran a ella un título legal fundamentado en 20 años de posesión de la tierra por parte de su padre. El patrón contrató un abogado para contrarrestar este esfuerzo. La agencia de Reforma Agraria decidió que la parcela pertenecía a los nuevos propietarios de la hacienda puesto que nunca había sido excluida del título global. El patrón dijo a los nuevos propietarios que ellos pagarían con sus vidas si insistían en sus reclamos sobre la parcela. Puesto que la oficina de Reforma Agraria insistió en que el lote pertenecía a la hacienda, los nuevos hacendados pagaron al patrón por su supuesta pérdida con la esperanza de tranquilizarlo. El patrón dijo entonces que tal vez él vendería el lote a la pareja ansiosa de tierra. (Existen caminos para burlar la cláusula de primera opción de la Ley de Reforma Agraria). El propietario vecino pagó una segunda cuota. Finalmente la agencia de Reforma Agraria entregó el título a la heredera, quien inmediatamente vendió la parcela a la pareja joven. En lo posterior el patrón ya no estuvo en condiciones de discutir las ventas de la tierra. 
La frecuencia y habilidad para mentir no tienen necesariamente una correlación positiva. Quienes con frecuencia mienten tienen la desventaja de que los que les oyen se vuelven cada vez más escépticos hacia ellos que hacia los que mienten con menos frecuencia. La gente de La Mar no miente cuando al hacerlo sus propósitos y sus intereses se debilitan. La mayor parte de las mentiras se dan con la intención de lograr alguna meta específica, aunque también mienten sin razón y por diversión. En general, mentir se considera una forma de conducta normal para todas las personas en algunas circunstancias y para algunas personas en todas las circunstancias.

La embriaguez es una circunstancia especial que altera las reglas de los procedimientos sociales normales, incluyendo la mentira. La embriaguez no excesiva puede considerarse como una oportunidad para hablar la verdad francamente, para excusarse de ciertas actitudes sociales que requieren tino, disimulo y autorestricción, lo cual normalmente se consigue con ayuda de mentiras. Hay una idea generalizada de que la embriaguez vuelve a una persona más propensa a mentir. Se piensa que las mentiras de los ebrios son más fantasiosas e inicuas que las de los sobrios.

De acuerdo con las normas éticas y morales locales, mentir es definitivamente malo. Es una falta moral que puede ocasionar problemas, incomodidades y desperdicio de esfuerzos. Sin embargo, desde el punto de vista individual, los problemas de otras personas no les conciernen en la medida en que no tengan derivaciones para el mentiroso. El problema moral puede disimularse y luego ser completamente ignorado si otros no prestan atención a ello. Se asume que en la naturaleza del hombre está transgredir las normas morales y que el perdón y el olvido son remedios apropiados en este caso.

A la pregunta de por qué la gente miente, los habitantes de La Mar tienen tres respuestas básicas: envidia, pobreza, o que no saben. La envidia es un concepto clave y se la considera como la fuente de muchas disputas y comportamientos incorrectos. Robos, enfermedades, chismes, mala suerte y venganzas pueden ser ocasionados por la envidia. La mentira es una de las formas en que la envidia se expresa. Por ejemplo, durante la pugna por las 3 hectáreas del difunto Taita Zhibry, tanto los propietarios vecinos como la joven pareja comenzaron una serie de historias fundamentadas en claras muestras de envidia de los unos a los otros. Cada uno alegaba que el otro estaba valiéndose de medios ilícitos y amenazas para comprar la tierra. Se acusaban mutuamente de hacer falsos reclamos, contratar abogados y 
realizar denuncias secretas al jefe de policía. Cada una de las partes argumentaba que detrás de estas maquinaciones el motivo era la envidia.

La pobreza se presenta como una excusa y justificación para mentir, robar, reñir, emborracharse y para la ignorancia. Puesto que cada uno insiste en que es pobre, al margen de su situación económica personal, se sigue que cada cual tiene una excusa para mentir. Por ejemplo, cuando Taita Atoe trataba de lograr apoyo en su reclamo de tierras, manifestaba con frecuencia que su pobreza le daba derecho legítimo a la tierra, justificando, por lo tanto, los medios de que se valía para tratar de adquirirla.

La tercera respuesta, el desconocimiento de las razones por la cual se miente es una táctica generalizada para evitar tópicos susceptibles de controversia cuando alguien no está seguro de si los va a hacer frente de la mejor manera posible. Por ejemplo, cuando se le preguntó a Taita Atoe que si el lote de tierra en disputa fue suyo por qué no lo ocupó o reclamó durante 20 años, su respuesta fue "no sé".

\section{La lógica de la mentira.}

La práctica de la mentira se fundamenta en varias premisas lógicamente relacionadas que se las admite como hechos de la vida dados por obvios. La primera premisa es la situación de pobreza social y económica. La gente se considera a sí mismo pobre, humilde, oprimida y ubicada en el fondo de la escala social y económica. Mentir viene a ser como un conjunto de estrategias para sobrevivir dada su posición de desventaja. Una segunda premisa es que otros mienten, engañan, engatuzan y esconden información. La única forma de funcionar y auto defenderse en esta situación es haciendo lo mismo. De acuerdo con una conformidad defensiva es necesario desarrollar una habilidad para mirar todo lo que se manifiesta en apariencia con escepticismo e interpretarlo mediante lo que uno escucha. Nada debe ser interpretado como algo que realmente tiene validez. De esto se sigue que si mentir es la conducta que se espera, no debe ser causa de sorpresa ni retaliación cuando esto se descubre.

Una tercera premisa consiste en que la vida es una lucha constante para crear y defender la posición socio-económica de cada uno y que hay constantes amenazas y agresiones en contra de esta posición. La mentira se usa como un arma defensiva y ofensiva en esta lucha. 
La fuerza de estas premisas hace de la mentira una forma de conducta válida y necesaria en la mayor parte de aspectos de la vida. Para relacionar la mentira a la estructura social yo la categorizaría de acuerdo con sus propósitos sociales y económicos. Los propósitos políticos, aquellos que tienen que ver con el logro y el ejercicio del poder estarían incorporados en una u otra de las categorías en relación con los contenidos específicos de los intereses correspondientes. En las siguientes dos secciones, doy ejemplos detallados de mentiras en cada categoría para ilustrar la amplia gama y variedad de mentiras que se usan, para luego mostrar cómo la mentira tiene su lugar en la conformación de la estructura social. Estas descripciones pueden ser consideradas como comunes y carentes de importancia, pero es precisamente por esta razón que merecen atención. Lo que - se da por hecho puede fácilmente ser mal interpretado.

\section{Las mentiras con fines económicos.}

Ocasiones para comprar y vender ofrecen los primeros ejemplos de la utilidad de las mentiras; no actuar de esta manera en estos casos sería tonto. El vendedor de un caballo dirá que viene de Loja, una provincia renombrada por sus finos caballos, o como una alternativa, que su padre es un famoso semental de propiedad de un vecino distante; dirá que el caballo es muy manso, que un niño de 3 años lo cabalga y que no pone ninguna dificultad para ser herrado. (El vendedor ha cansado al caballo cabalgándolo 6 horas con pesados sacos de arena para que dé la impresión de manso). "Este caballo tiene un hermoso paso fino, es extremadamente suave", lo que demostrará al vendedor manteniendo las riendas muy templadas y espoleando al caballo para que levante sus patas. "Este caballo también puede bailar", lo que lo logrará aplicándole más espuela. Un vendedor está obligado a hacer estas afirmaciones contrarias a lo que él sabe que es verdad, porque de otra manera encontraría difícil hacer la venta. El posible comprador sabe que si no se hacen afirmaciones fantasiosas acerca del caballo, es probablemente mucho peor de lo que muestra su apariencia.

El vendedor de una vaca dirá que da 5 galones diarios de leche, o que su madre daba esa cantidad si es que se trata de una vacona. El padre de la vaca fue un toro gigantesco, un Holstein pura sangre; esta mentira puede ser reforzada con una historia acerca de cómo la madre de la vaca fue llevada por la noche a la lechería de la hacienda, atravesando el río para que se cruzara allí con el fuerte Holstein. La quinta teta de la parte posterior de la 
ubre será señalada en el sentido de que también da leche, con lo que se hace una virtud de un defecto; "es muy joven, sólo tiene un año y medio, cuando crezca será mucho más grande. Es sumamente mansa, mi hija más pequeña le da agua y le cambia de lugar".

El grado de libertad del vendedor para mentir depende de la cantidad de información independiente accesible al comprador. Si el comprador conoce al animal, su historia y sus cualidades, el vendedor debe limitarse a hacer afirmaciones que no pueden ser verificadas. La cantidad de leche que da una vaca es conocida solamente por el ordeñador y por el propietario; por eso la gente frecuentemente miente acerca de esta cantidad. La ascendencia es también difícil de investigar, por lo cual los padres del animal en venta con frecuencia son criaturas de extremada belleza. Las madres de las ovejas siempre tienen partos múltiples, las gallinas ponen huevo todos los días, los puercos aumentan quince puerquitos y los padres de los perros son siempre inigualables cazadores, guardianes leales y nunca comen mucho.

Por supuesto comprar requiere una actitud contrapuesta. Un comprador dirá que el caballo es demasiado flaco, que probablemente tiene muy poco apetito. "Parece que tiene un defecto congénito en sus piernas haciendo que tropiece; es demasiado pequeño como para llevar cargas pesadas o hacer viajes largos; obviamente es perezoso y patea". Con los defectos establecidos se inicia el proceso de regateo. Las mentiras de ambas partes no tienen importancia en cuanto a lo que es el animal en sí, pero son necesarias para llegar a establecer un precio. Comprador y vendedor ponen en competencia sus habilidades verbales y sus personalidades con el mismo interés con que hacen el negocio. El que dé apariencia de ser más convincente, enfático y detallista acerca de las características del animal, estará en condiciones de lograr un precio más favorable.

Lograr acceso a medios de producción es una preocupación prioritaria. Dinero, herramientas, trabajo, empleo, pastos y tierra cultivable son los principales recursos que se necesita en la producción, y mentir puede ayudar a adquirir cada uno de ellos.

Se consigue dinero vendiendo algo (lo descrito anteriormente), por medio de un empleo (tratado por separado) y mediante préstamos. Al solicitar un préstamo es importante insistir en la obligación moral y social del prestamista, así como la importancia de la petición. Se dice que el prestamista es rico, que tiene dinero para gastar, se hace mención a que es 
compadre o pariente y se recuerda favores hechos por él. Verdades y mentiras se entremezclan haciendo que negar algo sea difícil. Una explicación compleja para negar la falsedad haría aparecer al prestamista como avaro. El que recibe el préstamo dirá que necesita dinero urgentemente para pagar a otro acreedor que le ha amenazado con iniciar acciones legales si es que la deuda no se cancela, o que necesita dinero para pagar una misa o llevar a su mujer al médico. Estas son razones de peso para obtener un préstamo y pueden ser verdaderas. Por otra parte, el solicitante puede querer el dinero para pagar por el bordado de su poncho o para comprar galletas y bebidas gaseosas en La Mar. Faltando más información, el prestamista tiene la obligación moral de contribuir a la religión, buena salud y defensa contra la injusticia.

El acceso a las herramientas de otra persona puede lograrse diciendo a él o a ella que se necesitan para hacer un trabajo en beneficio de otros. Por ejemplo, "necesito tu azadón para limpiar el canal de agua que nos pertenece a los dos". Azadón en mano, el que lo recibió en préstamo va a sembrar patatas. "Préstame tu hacha para poder ayudar a mi hermano a derribar algunos árboles ya que te ha ofrecido venderte tablones". Hacha en mano, el que la recibió en préstamo se dirige a limpiar su propio pedazo de bosque para una futura plantación. El acceso a las herramientas puede lograrse pidiéndolas como un favor, con la falsa promesa de devolverlas pronto y con un pequeño regalo para demostrar afecto; una vez que se han obtenido las herramientas, la promesa es olvidada y no se la vuelve a mencionar. Para el dueño de las herramientas, reclamarla sería desprestigiante ya que podría aparecer como egoísta e inconsiderado.

La mano de obra necesaria se consigue dentro del núcleo familiar y no hace falta mentir para lograr cooperación. Sin embargo, ciertas tareas requieren más trabajo que el que la familia puede proveer $\mathrm{y}$, a veces, mano de obra no esperada se torna disponible. Estas circunstancias dan oportunidad para manipular a otros con mentiras.

Un caso de mano de obra no esperada ocurrió cuando una muchacha de 14 años, Dolores, quedó huérfana. Las jóvenes contribuyen significativamente a la economía familiar, pueden cuidar todos los animales, ordeñar, dar agua y mudarles de lugar; pueden hacer queso, realizar tareas agrícolas como sembrar, deshierbar, cosechar y preparar el suelo; pueden cocinar, llevar leña y agua y cuidar de los niños. Los parientes más cercanos de Dolores eran dos hermanas casadas que inmediatamente entraron en 
competencia por atraer y tener bajo su control a la muchacha. Dolores maniobró esta situación a su favor haciendo que sus hermanas se enfrentaran; dijo que una de las hermanas no le alimentaba bien, que le hacía trabajar demasiado fuerte y que le golpeaba; luego expresó las mismas quejas acerca de la otra hermana. Las dos hermanas se valieron de estas habladurías e hicieron versiones acerca de ellas: la más joven dijo que la mayor era cruel e insensible y que quería tan sólo explotar a la pobre Dolores; que el marido la golpeaba sin causa, que su hermana era demasiado perezosa como para hacer los trabajos y que por esta razón quería tener a Dolores como esclava.

La hermana mayor respondió de la misma manera: que a la hermana menor realmente no le importaba la joven y que sólo quería usarla; que ella y su marido eran tan vagos que necesitaban que Dolores Ies mantenga. Dolores alternó entre las casas de sus dos hermanas tres veces a lo largo de cinco meses. Ahora vive con la hermana menor, donde trabaja fuerte pero no recibe mal tratamiento, una situación muy parecida a la que vivía con la otra hermana.

Como un epílogo de este caso, la disputa entre las dos hermanas no terminó con la decisión de Dolores. El marido de la hermana mayor es presidente de la Cooperativa, lo que le permite tomar decisiones relacionadas con las tierras. Sobre la casa de la hermana menor había una parcela de tierras de la Cooperativa; con matorrales y pastos donde ella y su marido clandestinamente pastaban sus animales. La Cooperativa puede vender derechos de pastar animales a sus miembros, pero no regalarlos. El presidente se quejó durante varias semanas de que gente desconocida estaba robando los pastos de la Cooperativa y luego decidió que se debía sembrar habas en la parcela en mención, y en la siguiente semana todos los miembros de la Cooperativa limpiaron y sembraron el área. Este fue un episodio de la revancha de la hermana mayor por la pérdida de su trabajadora.

El intercambio de trabajo es la forma usual mediante la cual las familias .obtienen ocasionalmente ayuda extra. Se realiza el trabajo bajo el presupuesto de que habrá una retribución del mismo cuando surjan necesidades; en la mayoría de estos casos este sistema funciona bien y la gente acude a trabajar para aquellos que trabajaron para ellos. Algunos individuos son más celosos en relación con su tiempo de trabajo o más sensibles acerca ; de sus conveniencias personales y pueden acudir a mentiras para excusarse de sus obligaciones; esta excusa puede consistir en que está enfermo, se ha resfriado, que su mujer está enferma y necesita atención 
constante o que tiene alguna tarea urgente que realizar; por ejemplo, el individuo que tiene que retribuir algún trabajo puede alegar que sus arvejas aún no han sido cosechadas y que si no lo hace ese día seguramente se pudrirán en la mata por lo que perderá diez mil sucres.

No faltan razones urgentes para estar ocupado si uno quiere usarlas. El campesino que quiere retribución al trabajo que él realizó sabe que estas son mentiras) pero también sabe que la insistencia y el enfrentamiento son transgresiones más graves que mentir, por lo que las deja pasar.

Las oportunidades de empleo están limitadas a días de trabajo en las haciendas y propiedades de tamaño medio, existen unos pocos puestos de trabajo a tiempo completo, generalmente mediante contratos anuales o contratos ocasionales para tareas específicas como carpintería, construcción o tejido. La competencia de puestos de trabajo puede ser intensa, dependiendo de la atractividad del empleo y de la etapa del ciclo agrícola. La mentira puede ser útil en esta competencia de diferentes maneras: puede ser usada para desanimar o excluir a otros de la competencia; se puede desanimar a un empleado generando dudas y malos entendidos entre él trabajador y el empleador y pueden, intencionalmente; crear dudas en; un empleador sobre quien está buscando un cargo en forma tal que un candidato respetable puede ser contratado sirviendo de pantalla a un trabajador poco confiable.

La persona que ambiciona el puesto; de administrador de uña hacienda comienza haciendo circular rumores, de que el actual administrador roba las herramientas de la hacienda, no se empeña en que trabajen los peones contratados por día y que es incompetente y tonto. Luego dice que el actual administrador va a ser cancelado pronto, qué él tiene informaciones confidenciales provenientes del patrón. Cuando el administrador conoce .esto se pone furioso y resuelto a retirarse. Solamente luego de mucha insistencia consiente en continuar, pero con la duda en su mente de que el patrón está jugando con él. Aunque un sólo incidente de este tipo no logra separar al administrador de la hacienda, una serie reiterada de ellos tiene efectos acumulativos y pueden finalmente culminar en la renuncia para evitar la supuesta cancelación.

Obligado a retirarse de la casa de su mujer, una persona trató de conseguir su propio trabajo-a tiempo completo en una hacienda. Dijo a la gente que él ya se había puesto de acuerdo para ser "huasicama" (cuidador y capataz general) en una hacienda que no tenía este cargo;-trató de convencer 
al patrón de que se necesitaba "huasicama". Dijo a su mujer que una vez que él llegara a ser "huasicama", el patrón le quitaría su" tierra a ella. Aún cuando el patrón no estaba convencido, todos creían que la hacienda tenía un nuevo "huasicama". El administrador interpretó la contratación de este nuevo puesto como un comentario negativo a sus gestiones en la hacienda, y también fue útil para intimidar a su mujer. La persona a la final fue a la ciudad y trabajó allí hasta que se superó la incompatibilidad.

En algunas haciendas el puesto de vaquero es muy atractivo, es bien pagado e incluye derechos a pastoreo de un cierto número de animales de propiedad del vaquero, uso de una casa, un caballo y provisión de alimentos. El vaquero tiene mucho tiempo libre cuando el ganado no está siendo contado, trasladado o curado. Cuando hay varios aspirantes al puesto de vaquero, es normal para cada uno de ellos dar a conocer que ya tiene el puesto. Esta mentira puede volverse más convincente mediante detalles adicionales acerca del acuerdo: el patrón va a construirme una casa en determinada parcela, pagarme exactamente S/. 5.000 mensuales, darme un equipo completo para trabajo en lluvia y permitirme usar el caballo café con cara blanca. Este tipo de mentiras ayuda a atascar la competencia. Para convencer al empleador, el solicitante debe enviar intermediarios para hablarle y convencer al patrón que no hay ninguna otra persona disponible para el empleo; luego el vaquero en perspectiva se presentará ante el patrón jurando por Dios que él dormirá con el ganado, nunca lo abandonaría día o noche, que es el más humilde y leal sirviente, que con mucha felicidad moriría si el patrón así lo ordenara, que él no tiene ningún miedo a los ladrones ni a los vecinos que se aprovechan del pasto, que su mujer, sus hijos y hermanos estarán con él para ayudarle a hacer un trabajo todavía mejor, pero que ellos posiblemente morirían de hambre contando tan sólo con pasto seco para comer, a menos que el patrón les dé una buena cantidad de arroz, azúcar, manteca, kerosene y fósforos.

Los empleadores no se dejan influenciar fácilmente por este tipo de mentiras, pero ellos captan, a través de las mentiras, el grado de deseo y sinceridad del solicitante; a pesar de la aparente contradicción, se trata de una parte del proceso en que la mentira entusiasta puede ser una demostración de fidelidad genuina, de deseo de trabajar; la experiencia personal y fuentes independientes de información acerca de los empleados en perspectiva dan al empleador otros criterios que sirven de base para la selección. La falta de información es una seria debilidad en cualquier trato y especialmente en el que tiene que ver con la contratación de empleados 
importantes. Así, los empleadores se defienden reuniendo tanta información como sea posible y recurriendo a la mentira para robustecer su posición como negociadores.

El acceso a pasto y tierra cultivable ajena a la propia tiene importancia vital entre los campesinos. Arrendamiento y tierras al partir son los medios más usuales para lograr este acceso, pero el robo y el accidente son alternativas. Los accidentes se los realiza valiéndose de animales que se liberan de sus estacas o entran a alimentarse en los pastos del vecino burlando las divisiones, o se ocasionan también porque los muchachos no amarran con suficiente seguridad a los animales o no cierran las puertas. Se recurre a mentiras para ocultar los casos de robo o accidente y evitar revanchas.

Una tarde un vaquero fue con su mujer y su hijo a amarrar sus ocho cabezas de ganado en el patio del patrón. El anochecer es normalmente buen tiempo para este propósito. Debido a una coincidencia inesperada, llegó la patrona cuando el vaquero y su familia estaban acarreando los animales y rápidamente los mandó a todos al otro lado del lindero. El vaquero reprendió a su mujer por ser tan descuidada como para permitir que el ganado cruzara el lindero. Al día siguiente llegaron el vaquero y su mujer trayendo quesillo como disculpa y echando totalmente la culpa a su hijo ocioso que no había amarrado apropiadamente a los animales que cruzaron el lindero sin darse cuenta. No mostraron dificultad alguna en mentir tan abiertamente frente a hechos en los que todos estaban involucrados. Pidieron a la patrona que perdone a su hijo negligente; la patrona los echó de la casa y canceló al individuo de su puesto de vaquero, exactamente lo que el individuo esperaba evitar con su visita en condición de suplicante. Al día siguiente regresó el vaquero con una botella de licor, papas cocidas y un cuy y su cuñado para que sirva de intermediario. Juraron eterna fidelidad, honestidad, responsabilidad en el trabajo, humildad; suplicaron que le multara por la falta y que le volviera a contratar; luego invitaron a la patrona a la casa del vaquero para una gran comida, más bebida y más promesas de absoluto e interminable servicio. Finalmente la patrona accedió, puesto que le habría sido bastante difícil reemplazar al vaquero en tan corto tiempo. Las mentiras le permitieron hacer esto con facilidad salvando su imagen de austeridad. Multó al vaquero con un mes de salario y le volvió a contratar.

Recuperado su puesto, el vaquero buscó cómo resarcirse de su pérdida. Supo que uno de sus vecinos había arrastrado algunos troncos una corta distancia a través de la tierra de su patrona, dejando el pasto aplastado. 
Fue donde su vecino y le dijo que su patrona le había multado el equivalente a un mes de sueldo por el daño hecho por la arrastrada de los troncos y pedía compensación; no queriendo enfrentarse a la presumiblemente furiosa patrona, el vecino pagó al vaquero.

El caso que acabo de describir no es común en la medida en que el propietario del pasto sorprendió al ladrón en pleno acto. En la mayoría de los casos no hay testigos de la ubicación de los animales o de su retiro luego de que han comido. Simplemente se encuentra el pasto comido, el maíz pisoteado, falta dé choclos o una extensión de sembrío de papas dañado por puercos que ya se han ido. Con frecuencia los propietarios saben quién robó su pasto o sus cultivos. Conocen los hábitos de sus vecinos y son excelentes intérpretes de rastros y de huellas, pero la confrontación no es una forma aceptable de comportamiento y el sondeo, aunque sea delicado e indirecto, comúnmente ocasiona la negación de conocimiento alguno del asunto.

"No sé" es una de las mentiras más usadas. El uso que de ella hizo Taita Atoe fue ya mencionado; se emplea de la misma manera que la ostentación de pobreza, humildad, desesperación e inocencia. El desconocimiento de todos los asuntos que puedan acarrear consecuencias es parte de la presentación de un campesino, parte de su estrategia de defensa para protegerse a sí mismo. No solamente el ladrón del pasto no tiene idea de quién pudo haber puesto los animales en el pastizal ajeno, sino que el vecino que vio y reconoció ciertos-animales en el pasto dirá que no vio ni sabe nada. La gente informará acerca del ladrón solamente si tiene una fuerte razón personal para hacerlo, pero en ningún caso por motivaciones de justicia o por un impulso moral.

\section{La mentira con fines sociales.}

La posición social en La Mar se define por la raza, la condición económica y el carácter o personalidad; cada uno de los componentes interactúa en relación con los otros. Mientras cada individuo tiene una posición social reconocida en términos generales de acuerdo con la raza, situación económica e identidad personal, el puesto específico en la sociedad con relación a los otros es negociable y puede mejorar o deteriorarse mediante un esfuerzo concertado. La mentira puede ser efectiva elevando la imagen pública de unas personas y rebajando la de otras.

La frontera racial entre indios y blancos es una línea bien establecida de conflicto social. Rutinariamente indios y blancos se denigran unos a otros 
en base de identidad racial. Los hechos concretos de una situación son poco relevantes cuando un problema o un mal entendido se genera entre miembros de dos grupos. Los indios son animales, ladrones, estúpidos, irracionales, sucios, perezosos, borrachos, violentos y, por supuesto, mentirosos. Los blancos son malvados, abusivos, incomprensibles, fanáticos, tramposos, perezosos, paternalistas $\mathrm{y}$, por supuesto, mentirosos. Las historias inventadas para explicar estos adjetivos atribuidos a cada grupo se aceptan con alguna credibilidad entre los miembros del grupo opuesto, ya que las peculiaridades son generalmente consideradas verdaderas.

Como se mencionó antes, la estratificación económica se entremezcla con la frontera racial. Tanto blancos como indios están en competencia por los mismos recursos y trabajan de igual manera. Los campesinos más pobres de ambos grupos étnicos no han conformado lazos de solidaridad de clase, no colaboran en una lucha conjunta contra los más ricos. De manera similar, indios y blancos ricos no ven que tienen mucho en común. Creo que la gente de La Mar contribuye a mantener la división étnica como un factor de una estrategia más amplia para categorizar el universo social entre colaboradores y competidores, inofensivos y peligrosos, generosos y egoístas La división racial simplifica esta tarea ya que categoriza a priori un amplio sector de la comunidad. Integrantes de la misma clase se consideran entre sí los principales competidores.

Además del propósito estratégico para el que sirve, hay razones sociales presionantes que torna la frontera racial conflictiva. En la sociedad ecuatoriana más amplia, lo blanco está asociado con status alto, riqueza y poder. Los blancos de La Mar, no importa su pobreza y carencia de poder, usan de su blancura para colocarse en un peldaño más elevado que sus vecinos indios. Los indios, plenamente conscientes de la categoría social que les coloca en el fondo, miran al sistema como injusto pero inexorable. Como defensa contra este hecho social, refuerzan activamente la frontera racial mediante opiniones negativas acerca del otro lado.

La mentira a través de los estratos socio-económicos se considera en ambas partes como un elemento integral de la interacción normal. Los campesinos ricos y patrones esperan ser mentidos por los pobres como una especie de impuesto pará ocupar una mejor porción. El campesino pobre acepta mentiras de su superior como uno de los derechos conferidos a su elevado status. En la práctica la mentira es uno de los pocos medios efectivos para manipular a los superiores en términos sociales en una sociedad en la que algunos de los pilares de la relación señor-siervo aún se encuentra en pie. 
Obediencia ciega se espera de los empleados y los servicios personales se piden y dan de acuerdo con la posición social; con la ayuda del licor se besa con reverencia las manos y los pies de un patrón, y en un pasado reciente se daba palizas a un peón que ocasionaba el más leve disgusto. Así, mientras los patrones y los campesinos ricos usan su autoridad y la amenaza de fuerza física a través de la policía y funcionarios judiciales para controlar a sus inferiores, los peones y los campesinos pobres se valen de mentiras y 'otros engaños para manipular y denigrar a sus superiores.

El administrador de una gran hacienda lechera sugiere a un visitante de la ciudad que su patrón es ignorante e incompetente para dirigir la empresa, que falla en dar cuidado apropiado a las vacas y ocasiona daños a los sembríos debido a órdenes equivocadas de cultivo; si estas funciones estarían a su cargo, él insinúa, las cosas serían completamente distintas. Los trabajadores de esta hacienda describen al hijo de la patrona en términos de mofa; según ellos esta frecuentemente borracho, no sabe nada de agricultura ni de lechería, no hace otra cosa que efectuar recorridos en grandes caballos dando órdenes inútiles. De esta manera los desaventajados socialmente están en condiciones de insinuar que sus superiores no valen la pena para su posición elevada.

Un empleado indígena informa a su patrón que una familia blanca vecina, que el empleado detesta, ha robado los pollos del patrón; en otra ocasión, que posiblemente escondieron ganado robado en el bosque del patrón y, en otro caso, que han robado plantas del jardín. Con este tipo de invenciones el empleado manipula a su patrón para que amenace y posiblemente castigue a los vecinos para su total satisfacción y desacuerdo con lo que conoce que es verdad.

La mentira dentro de un estrato social está frecuentemente motivada por la intensa competencia por recursos y prestigio que se da internamente, más que entre los diferentes estratos. Los odios más intensos y los conflictos de más larga duración están entre gente que tiene un status muy similar, así como situación económica y poder. Dada la similitud entre los rivales, la mentira representa un recurso libre y ajeno y se usa con una intensidad y frecuencia no observada en un enfrentamiento entre personas de diferentes estratos, condición social y raza.

La familia Urna dice que los Tocte se han vendido a la hacienda donde trabaja un Tocte; que ellos piensan que se han hecho caballeros 
blancos y que andan engreídos. Como prueba de la arrogancia de los Tocte señalan que una de las hijas jóvenes de un Tocte va a la escuela (lo que se requiere por una regulación de la Cooperativa). De acuerdo con los Urna, los Tocte no cumplen con las obligaciones para con la Cooperativa, no asisten a todas las reuniones ni participan en todos los días de trabajo colectivo; en lugar de ello mandan reemplazos inútiles, por lo que deberían ser multados. Los Tocte se emborrachan con mucha frecuencia y pelean. El ganado de los Tocte es flaco y feo, y cuando una res muere es, con seguridad castigo de Dios por sus fechorías.

De acuerdo con los Tocte, los Urna están siempre maldiciendo la hacienda y el patrón debería castigarles por sus mentiras. Los lima son amenazantes y mal educados, abusan de los niños pequeños de los Tocte cuando los encuentran solos en el camino y agreden a los Tocte adultos si es que tienen oportunidad. Los Urna engañaron a los Tocte en una compra de tierra manipulando maliciosamente las regulaciones de la Cooperativa. En resumen, estas historias revelan un profundo antagonismo entre las dos familias basado en parte, en una competencia directa por recursos como tierra y, en parte, por el deseo de aplastar social y políticamente al vecino más similar.

Situaciones conflictivas familiares entre blancos siguen un modelo idéntico; el contenido de las mentiras y la naturaleza de los perjuicios reales importa menos que la posibilidad de minar el prestigio del enemigo elevando el propio. Entre los peones dependientes de una hacienda -anterior a la reforma agraria- había dos familias blancas que eran partidarias y servían al patrón en similares condiciones. Con la reforma agraria el patrón vendió a cada una de ellas cerca de 50 hectáreas de tierra y 20 años después las dos familias son ricas de acuerdo con los parámetros locales. Estas dos familias se odian entre sí con pasión. Cada familia desprestigia la conducta pasada y presente, así como la personalidad y apariencia de la otra con una larga serie de abominaciones.

Los cuentos son más exitosos cuando ellos inducen a una tercera parte a actuar contra la familia enemiga, o les niega acceso a un recurso. Por ejemplo, constituye un placer convencer a un comprador de ganado no entrar en negocios con el enemigo so pretexto de que su ganado tiene enfermedades en las pezuñas y en el hocico y/o que ha sido robado. Ocasiona satisfacciones similares advertir a un empleador en mientes/ no contratar a ninguno de los 
enemigos porque no son cuidadosos, son perezosos y en realidad lo único que quieren es ir a ver qué hay que robar.

\section{Mentira y estructura social: Conclusiones.}

Como se ha dado a conocer en los anteriores ejemplos, la mentira es una parte integral de la vida cotidiana en La Mar. Se la practica pragmáticamente con la intención de manipular situaciones y competir por recursos. Se encuentra entretejida en la cultura local, se la aprende simultáneamente con el lenguaje y se la ejerce con un grado variado de habilidad y frecuencia por la mayoría de los miembros de la sociedad. Debido a que la mentira es conocida y en la práctica relacionada con demostraciones de pobreza y amenazas multilaterales de usurpación de los vecinos, sugiero que se trata de un complejo de rasgos culturales y sociales del sistema de hacienda que fomentó este tipo de percepciones.

En otras palabras, la mentira, junto con sus supuestas justificaciones o percepciones de un mundo duro, es parte de una amplia herencia cultural desarrollada bajo la institución de la hacienda y mantenida con adaptaciones al cambio de la estructura social.

Lo que se ha escrito acerca del cambio' socio-cultural está lleno de ejemplos de supervivencias Tylorianas que no solamente han sobrevivido sino que se han adecuado como en su casa en el mundo moderno. Uno de los elementos definitorios diacríticos del campesinado es su tenaz esfuerzo para mantener la tradición y, con frecuencia, la adaptación de la tradición a las circunstancias cambiantes. Maccoby (1967: 336-346) en un reportaje sobre un estudio de actitudes en el desarrollo de un proyecto llevado a cabo en una aldea mexicana, describe la continuidad de actitudes y formas de comportamiento modeladas bajo el sistema de hacienda mucho tiempo después de que fuera abolido dice:

"En la aldea actualmente, pese al gran mejoramiento de condiciones de vida de los campesinos, persisten las actitudes sicológicas del peón. Los campesinos carentes de fe en sí mismos aún buscan patronos ante los cuales actúan en condiciones de humildes suplicantes. Actitudes de competitividad y falta de confianza típicas de todos los campesinos se enraizaron profundamente con la experiencia de la hacienda y persisten aunque están en conflicto con el ideal revolucionario de cooperación". 
Estas características son altamente cercanas a ciertas actitudes y formas de comportamiento en La Mar.

Destaco esto porque me afectó fuertemente el hecho de que durante mi primera visita al sector de La Mar un agricultor me informó duramente que el tiempo de los gamonales ${ }^{3}$ había pasado y que, por lo tanto, no necesitaba oírme o entrar en negocios conmigo por ningún concepto.

Como cuidador legalmente nombrado de la propiedad que yo había ido a conocer, este agricultor tenía la obligación por ley de mostrármela, lo que luego lo hizo atendiéndome con extrema generosidad durante el proceso. La idea de "el tiempo de los gamonales" estaba claramente adherido a su mente, lo que posteriormente encontré que estaba omnipresente entre todos los vecinos. El caso de este agricultor concreto ilustra, de manera condensada, algunas de las contradicciones aparentes pero en realidad resueltas de la secuencia continuidad y cambio. El es uno de los campesinos más ricos de la parroquia y continúa enriqueciéndose. Es propietario de alrededor de 60 cabezas de ganado y 300 hectáreas de tierra excelente junto al rio. Sus animales, desde el ganado hasta los cuyes, son de raza superior. Sin embargo insiste que es sumamente pobre y que a duras penas vive a un nivel de subsistencia con. el sudor de su frente. Cuando habla del tiempo pasado de los gamonales se torna vehemente, aunque con mucha rapidez actúa en condición de humilde sirviente y suplicante cuando le conviene. Se regocija con la desaparición de los gamonales, pero en su propia empresa está muy cerca de convertirse en uno de ellos, lo que le agradaría enormemente. Nada le gustaría más que liquidar y arruinar a su vecino más cercano y principal rival quien, precisamente porque este vecino es blanco, le considera un indio bestia. Esta serie de contradicciones presentes en un hombre ilustra en un microcosmos la persistencia de la hacienda a pesar de que ha sido superada.

Contrariamente a las desaprobaciones hechas por los moralistas (i.e. Bok: 1979), mentir ayuda a hacer posible la vida social. La verdad y la confianza no se necesitan como bases de la acción social y la cohesión comunitaria. Como la gente de La Mar lo demuestra, es posible mentir, engañar y robar a los vecinos y simultáneamente trabajar, cooperar y respetarse unos a otros en forma suficiente para producir, reproducir y coexistir. Puede esto no ser placentero, pero funciona.

En un mundo percibido y experimentado como un hogar estrecho, mentiras y ficciones crean una holgura en las relaciones sociales que 
posibilitan ataques y defensas contra competidores o las dos cosas simultáneamente. La mentira permanente fuerza a la gente a dudar unos de otros, a esperar lo peor de los demás y a actuar defensivamente en su toma de decisiones. Esta misma actitud defensiva proporciona un margen de seguridad, de lucha por la cual los campesinos son renombrados. No les agrada ser ensanchados demasiado, ni en términos sociales ni en económicos.

La mentira ocasiona mucha pérdida de tiempo, esfuerzo y recursos que se manifiestan a niveles de comunidad en una productividad más baja en términos medios y en una débil solidaridad. Cooperación permanente y amplia con la comunidad, a la vez que organización, se tornan sospechosas aunque hay acuerdo en que podrían ser beneficiosas. Por ejemplo, casi todas las familias producen quesillo para venderlo en la feria del viernes a las cholas ${ }^{4}$ compradoras de Azogues, la capital del cantón. Todos saben que los compradores han alterado las balanzas para pesar el queso, que reducen el peso luego de que leen lo que la balanza marca y que se ponen de acuerdo en fijar el precio y mantener el costo $20 \%$ más bajo que el de Azogues. Si tan sólo un grupo pequeño de productores de quesillo se organizara, podrían romper con el control de las cholas compradoras en el mercado, forzarlas a pesar y pagar justamente e inclusive amenazarlas con vender directamente al intermediario en Azogues; una medida de este tipo beneficiaría a todos, pero aparentemente no se le ha ocurrido a nadie. Sin embargo se quejan triste y amargadamente de los abusos de las compradoras de quesillo y continúan vendiéndolo de la misma manera. Ninguno se atreve a provocar la rabia de las compradoras porque un boicot de la compradora contra alguna de las vendedoras económicamente sería desastroso y su status bajaría con los epítetos de alzada y creída.

Así las consecuencias de la mentira permanente para la estructura social posibilita un acuerdo interpersonal a la vez que genera desacuerdos. El presupuesto de confianza, honestidad, generosidad, humildad y extrema pobreza bajo el cual el trabajo y la cooperación se desarrollan, crean una infraestructura dentro de la cual se practica la mentira para atraer los frutos del trabajo y la cooperación en provecho dé cada uno. Puesto que todos participan en ella, lo expresado por los filósofos de la moral acerca del efecto nefasto de la mentira sobre las bases de la sociedad está infundado; además la mentira puede tornar interesante la vida. ¿Quién podría imaginarse que el Presidente de la República va a confiscar la tierra de las cooperativas, separar 
de ellas a todos los indios y devolverlas al gamonal que va a sembrar rosas? (Ejemplo auténtico).

\section{NOTAS}

(1) Huasipungo: pequeño pedazo de tierra de una hacienda entregado en usufructo a un trabajador y a su familia como pago total o parcial por determinado número de días de trabajo en la hacienda. Generalmente incluye derechos a pastoreo para animales del trabajador, leña y agua.

(2) Muchos blancos de La Mar, desde el punto de vista del genotipo, no se distinguen de los escandinavos. Pertenecen ellos a las más viejas familias del área, posiblemente descendientes de inmigrantes españoles que se afincaron durante el periodo colonial en calidad de campesinos y no de terratenientes.

(3) Un gamonal es literalmente una persona propietaria de una amplia extensión de tierra, pero el término lleva consigo implicaciones denigrantes relacionadas con individuo que abusa y explota a los trabajadores.

(4) Chola es una mujer que antes fue india, o cuyos padres fueron indios pero que se encuentra en proceso de convertirse en mestiza o blanca. El término implica residencia urbana, pero con un estilo de vida rural en un pasado reciente. 


\section{BIBLIOGRAFIA}

Bock, Sísela

1979 Lying: Moral Choice in Public and Prívate Life. New York: Random House.

Chagnon, Napoleón A

1974 Studying the Yanomamö New York: Holt, Rinehart and Winston, Inc.

Fals-Borda, Orlando

1962 Peasant Society in the Colombian Andes: A Sociological Study of Saucío. Gainsville: University of Florida Press.

Foster, George M.

1965 Peasant Society and the Image of Limited Good. American Anthropologist 67: 293-315.

1967 Tzintzuntzan, Mexican Peasants in a Changing World. Boston: Little, Brown and Company.

Mccoby, Michael

1967 Love and Authority: A Study of Mexican Villagers. In Peasant Society, a Reader. Jack M. Potter, May N. Díaz, and George M. Foster, eds. pp. 336-345. Boston: Little, Brown and Company.

Reichel-Dolmatoff, Gerardo and Alicia

1961 The People of Aritama. Chicago: University of Chicago Press. 
